\title{
Massive open online course as a component of the blended learning program on basic life support and automated external defibrillation
}

\section{Alexei Birkun ${ }^{1}$, Lesya Frolova ${ }^{2}$}

\author{
${ }^{1}$ Medical Academy named after S. I. Georgievsky of V. I. Vernadsky Crimean Federal University, \\ Simferopol, Russian Federation; e-mail: birkunalexei@gmail.com \\ 2 State Budgetary Healthcare Institution of Republic of Crimea «Crimean republican center of disaster \\ medicine and emergency medical services», Simferopol, Russian Federation
}

Purpose of the study. To evaluate the effectiveness of basic life support (BLS) and automated external defibrillation (AED) training through a blended learning approach, utilizing a massive open online course (MOOC) as an alternative to on-site theoretical tuition.

Materials and methods. Nonmedical university students and nursing students were randomized to a classroom training (1-hour lecture, 3-hour hands-on training; $\mathrm{n}=66$ ) or blended training (1hour MOOC [stepik.org/org/cscem], 3-hour hands-on training; $n=67$ ) in BLS with AED. After 2,5 the training, resuscitation performance in a 2 simulated scenario was video recorded and further evaluated in a blinded manner using a checklist. Objective performance measures were registered with the Resusci Anne QCPR mannequin. Knowledge of BLS and readiness to attempt resuscitation were assessed pre- and post-training.

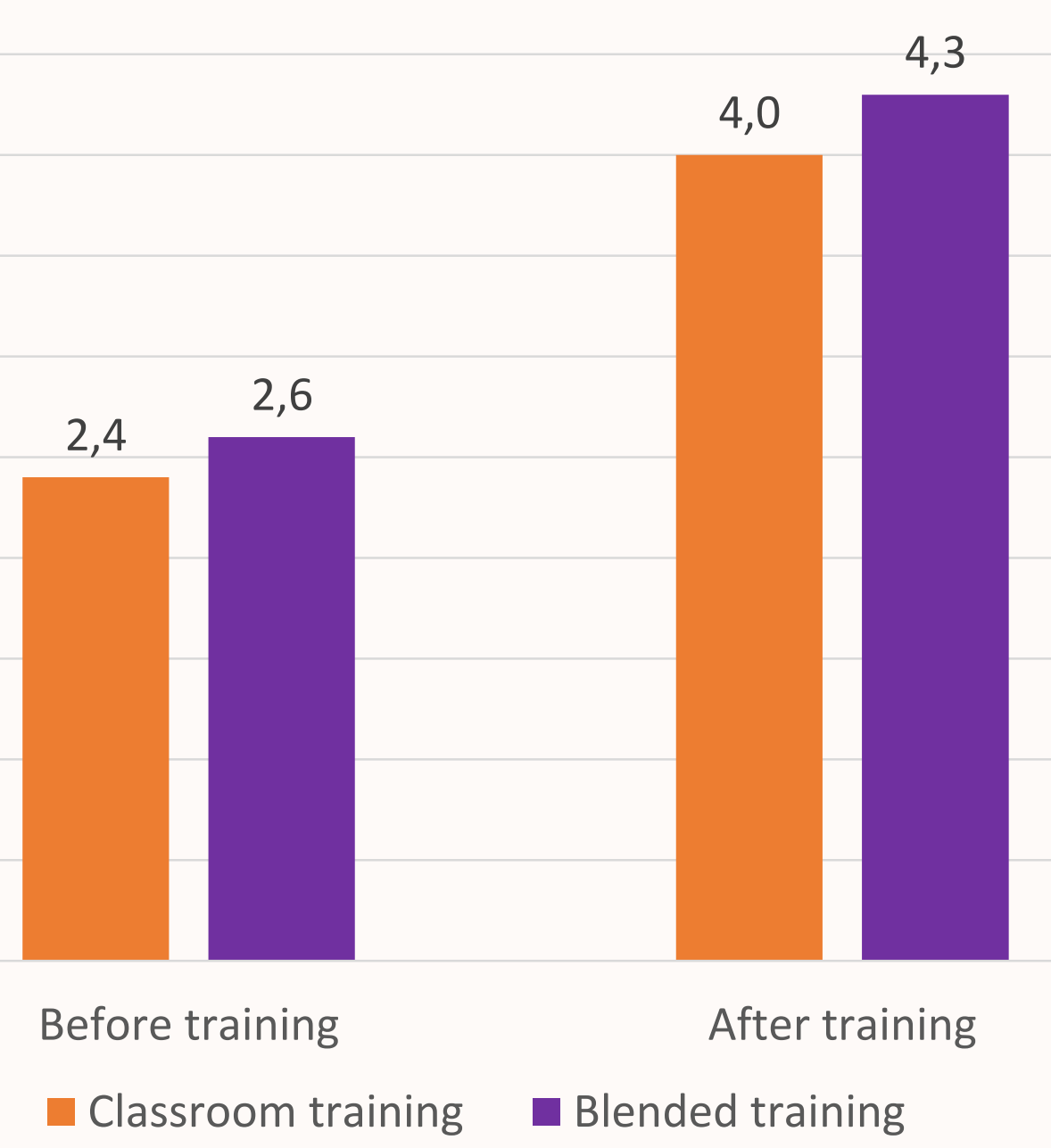

Figure. Self-perceived resuscitation knowledge.

Results. The study was completed by 55 and 39 participants from the classroom training and blended training group, respectively. In the classroom training group, more participants had previously received training in resuscitation ( $36 \%$ vs. $13 \%$; $p<0.05$ ). Nevertheless, at baseline, this group was not superior as for the levels of willingness to attempt resuscitation or resuscitation knowledge. After training, both groups demonstrated comparable improvement in readiness to attempt resuscitation (both groups - from 3.6 to 4.4 points) and in self-perceived resuscitation knowledge (see Figure). Objective assessment of knowledge revealed no between-group differences. Higher chest compression rate in the blended learning group (116.0 vs. 109.4, $p=0.006$ ) was the only difference noted in skills assessment. However, the proportion of compressions with correct rate was similar $(p>0.05)$. Both groups reported high satisfaction with attended training.

Conclusions. Blended learning, utilizing the MOOC instead of the instructor-led theoretical tuition, is non-inferior to the traditional classroom training in BLS and AED. This approach may decrease instructor burden, improve cost-effectiveness, and enhance accessibility of resuscitation training programs. 